\title{
Computational Study of C-H Bond Strengths in Polyfluoroalkanes
}

\author{
Paul Marshall* and Martin Schwartz* \\ Department of Chemistry, University of North Texas, Denton, Texas 76203-0068, and Center for \\ Computational Modeling of Nonstructural Materials, Wright Laboratory, Materials Directorate, \\ Wright-Patterson AFB, Ohio 45433
}

Received: December 5, 1996; In Final Form: February 12, $1997^{\otimes}$

\begin{abstract}
Ab initio energies obtained at the MP2/6-311+G(3df,2p)//MP2/6-31G(d) level of theory have been employed in isodesmic reactions to obtain $\mathrm{C}-\mathrm{H}$ bond dissociation enthalpies at $298 \mathrm{~K}$ for a variety of $\mathrm{C}_{1}-\mathrm{C}_{4}$ hydrofluorocarbons. There is good accord with the experimental data that are available for $\mathrm{C}_{1}$ and $\mathrm{C}_{2}$ species. Several relations between structure and BDE have been noted, and trends where $-\mathrm{H}$ and/or $-\mathrm{CH}_{3}$ groups are replaced by $-\mathrm{F}$ and/or $-\mathrm{CF}_{3}$ were rationalized in terms of the inductive effect, involving $\sigma$ and/or $\pi$ electron donation and withdrawal. The strongest predicted $\mathrm{C}-\mathrm{H}$ bonds are $\left(\mathrm{CF}_{3}\right)_{3} \mathrm{C}-\mathrm{H}$ and $\left(\mathrm{CF}_{3}\right)_{2} \mathrm{CH}-\mathrm{H}$, both with BDEs of $450 \mathrm{~kJ} / \mathrm{mol}$, which are up to about $45 \mathrm{~kJ} / \mathrm{mol}$ higher than the hydrocarbon analogs.
\end{abstract}

\section{Introduction}

Hydrofluorocarbons (HFCs) are widely employed as substitutes for chlorofluorocarbons, which lead to chlorine-catalyzed stratospheric ozone depletion, for applications including refrigeration and cleaning. $\mathrm{HFCs}$ such as $\mathrm{CF}_{3} \mathrm{CHFCF}_{3}$ are proposed as substitutes for the fluorocarbons $\mathrm{CF}_{4}$ and $\mathrm{C}_{2} \mathrm{~F}_{6}$, presently employed as fluorine atom sources in silicon wafer plasma etching and chamber cleaning processes but which have high global warming potentials (GWPs). ${ }^{1} \quad \mathrm{CF}_{3} \mathrm{CHFCF}_{3}$ is also recommended as a fire extinguishing agent to replace $\mathrm{CF}_{3} \mathrm{Br}$ and other halons in certain applications, ${ }^{2}$ because these brominecontaining agents also lead to ozone depletion. Thermodynamic and kinetic data for HFCs are needed to understand their behavior in combustion and plasma environments, as well as their subsequent fate in the atmosphere.

An ongoing emphasis of our group is investigation of the thermochemistry and kinetics of HFCs and other halocarbons via computational methods. ${ }^{3-7}$ A fundamental property that controls the chemistry of HFCs is the $\mathrm{C}-\mathrm{H}$ bond dissociation enthalpy (BDE). $\mathrm{C}-\mathrm{H}$ bonds are more labile than the $\mathrm{C}-\mathrm{C}$ or $\mathrm{C}-\mathrm{F}$ bonds and therefore dominate the chemistry of HFC flame suppressants and plasma etchants, and it is primarily $\mathrm{OH}$ attack at $\mathrm{C}-\mathrm{H}$ bonds that reduces the atmospheric lifetime, and thus the GWP, relative to totally fluorinated molecules. ${ }^{8}$ While there have been numerous experimental studies of the enthalpies of formation (from which BDEs are simply derived) of fluoromethanes and ethanes, and their associated radicals, ${ }^{9,10}$ there is a paucity of equivalent thermodynamic data for fluoropropanes and butanes of practical interest.

The aim of the present work is to address this deficiency via $a b$ initio calculations. There have been previous applications of ab initio methods, to $\mathrm{C}_{1}$ and $\mathrm{C}_{2}$ HFC species, where BACMP4 ${ }^{10}$ and MP2/6-311G(d,p $)^{11-15}$ data were obtained. In the present work, MP2/6-311+G(3df,2p) data for $\mathrm{C}_{1}$ to $\mathrm{C}_{4} \mathrm{HFCs}$ were analyzed to obtain the $\mathrm{C}-\mathrm{H}$ BDEs and to investigate the influence of various structural factors on bond stability. Primary, secondary, and tertiary $\mathrm{C}-\mathrm{H}$ bonds were investigated, as well as the effects of $\mathrm{F}$ and $\mathrm{CF}_{3}$ substitution in alkanes.

\section{Calculations}

The $a b$ initio calculations were carried out using the GAUSSIAN-94 ${ }^{16}$ suite of programs on an SGI R10000 Irix-2 worksta-

${ }^{\otimes}$ Abstract published in Advance ACS Abstracts, March 15, 1997.
TABLE 1: Comparison of Experimental and Calculated Bond Dissociation Energies in Fluoromethanes ${ }^{a}$

\begin{tabular}{|c|c|c|c|c|c|}
\hline species & $\operatorname{expt}^{b}$ & G2 & $\begin{array}{c}\mathrm{MP}^{c} \\
6-311 \mathrm{G}(\mathrm{d}, \mathrm{p})\end{array}$ & $\begin{array}{c}\left.\mathrm{QCISD}^{\mathrm{Q}} \mathrm{T}\right)^{c} \\
6-311 \mathrm{G}(\mathrm{d}, \mathrm{p})\end{array}$ & $\begin{array}{c}\mathrm{MP}^{c} \\
\text { 6-311+G } \\
\text { (3df,2p) }\end{array}$ \\
\hline $\mathrm{CH}_{3} \mathrm{~F}$ & $\begin{array}{l}441.0 \pm 18^{d} \\
418.0 \pm 11.9^{e}\end{array}$ & 426.8 & $\begin{array}{l}423.2 \\
(-3.6)\end{array}$ & $\begin{array}{l}423.2 \\
(-3.6)\end{array}$ & $\begin{array}{r}426.9 \\
(0.1)\end{array}$ \\
\hline $\mathrm{CH}_{2} \mathrm{~F}_{2}$ & $\begin{array}{l}416.2 \pm 15^{d} \\
422.5 \pm 8.6^{e}\end{array}$ & 428.5 & $\begin{array}{l}424.5 \\
(-4.0)\end{array}$ & $\begin{array}{l}425.4 \\
(-3.1)\end{array}$ & $\begin{array}{l}427.9 \\
(-0.6)\end{array}$ \\
\hline $\mathrm{CHF}_{3}$ & $\begin{array}{l}442.7 \pm 6^{d} \\
448.2 \pm 8.8^{e}\end{array}$ & 449.2 & $\begin{array}{l}445.8 \\
(-3.5)\end{array}$ & $\begin{array}{l}447.2 \\
(-2.0)\end{array}$ & $\begin{array}{l}448.1 \\
(-1.2)\end{array}$ \\
\hline
\end{tabular}

${ }^{a}$ Bond dissociation energies at $298.15 \mathrm{~K}\left[D_{298}\right]$ in $\mathrm{kJ} / \mathrm{mol} .{ }^{b}$ Experimental BDEs, in $\mathrm{kJ} / \mathrm{mol} .{ }^{c}$ Quantities in parentheses are deviations from G2 BDEs. ${ }^{d}$ From data in ref $9 .{ }^{e}$ From data in ref 10.

tion and a Cray C-90 supercomputer. Gaussian-2 (G2) ${ }^{17}$ calculations were performed on $\mathrm{CH}_{4}$ and the four fluoromethanes. The ground-state energies were used to determine $\mathrm{C}-\mathrm{H}$ BDEs at $298.15 \mathrm{~K}$ for the latter series using the appropriate isodesmic reactions (vide infra). Several component energies were also used to calculate alternative values for the BDEs in order to assess the effect of basis set and electron correlation on the quality of computed results. The calculated and experimental dissociation enthalpies are shown in Table 1; experimental values were determined from enthalpies of formation of the molecules and radicals in the compilations of Gurvich et al. ${ }^{9}$ and Zachariah et al. ${ }^{10}$

Energy and frequency calculations were performed on a series of polyfluorinated ethanes, propanes, and isobutanes and related radicals, whose structural formulas are contained in Table 2 (ethanes, nos. 2-6; propanes, nos. 7-12; isobutanes, nos. 1316). The zero-point energies (ZPE) were determined by $\mathrm{HF} /$ 6-31G(d) geometry optimizations and subsequent frequency calculations. Frequencies were scaled by the standard factor of $0.8929 .{ }^{18}$ Geometries were then reoptimized at the MP2 $=$ full/ 6-31G(d) level, and single-point energies were calculated with the MP2 $=\mathrm{fc} / 6-311+\mathrm{G}(3 \mathrm{df}, 2 \mathrm{p})$ basis. Values of $E_{0}$ in Table 2 are the energies including the scaled ZPE.

\section{Results and Discussion}

It is possible to use $a b$ initio energies to calculate BDEs directly from the homolytic dissociation equation:

$$
\mathrm{RH} \rightarrow \mathrm{R}^{\bullet}+\mathrm{H}^{\bullet}
$$


TABLE 2: Bond Dissociation Energies in Polyfluoroalkanes

\begin{tabular}{|c|c|c|c|c|c|}
\hline no. & species $^{a}$ & $\mathrm{ZPE}^{b, c}$ & $E_{0}^{c, d}$ & $D_{298}(\text { calc })^{e}$ & $D_{298}(\text { expt })^{f}$ \\
\hline \multirow[t]{2}{*}{1} & $\mathrm{CH}_{4}$ & 0.042658 & -40.363008 & & $438.9 \pm 0.6^{g}$ \\
\hline & $\mathrm{CH}_{3}{ }^{\circ}$ & 0.027653 & -39.703716 & & \\
\hline \multirow[t]{2}{*}{2} & $\mathrm{CH}_{3} \mathrm{CH}_{2}(-\mathrm{H})$ & 0.071217 & -79.548989 & 426.7 & $420.6 \pm 4.3$ \\
\hline & $\mathrm{CH}_{3} \mathrm{CH}_{2}{ }^{\circ}$ & 0.056554 & -78.894225 & & \\
\hline \multirow[t]{2}{*}{3} & $\mathrm{CH}_{2} \mathrm{FCH}_{2}(-\mathrm{H})$ & 0.065306 & -178.683944 & 435.1 & $433.5 \pm 1.9$ \\
\hline & $\mathrm{CH}_{2} \mathrm{FCH}_{2}^{\circ}$ & 0.050729 & -178.025984 & & \\
\hline \multirow[t]{2}{*}{4} & $\mathrm{CHF}_{2} \mathrm{CH}_{2}(-\mathrm{H})$ & 0.058502 & -277.836195 & 443.1 & \\
\hline & $\mathrm{CHF}_{2} \mathrm{CH}_{2}{ }^{\circ}$ & 0.044191 & -277.175169 & & \\
\hline \multirow[t]{2}{*}{5} & $\mathrm{CF}_{3} \mathrm{CH}_{2}(-\mathrm{H})$ & 0.050779 & -376.995984 & 447.9 & $446.5 \pm 4.5$ \\
\hline & $\mathrm{CF}_{3} \mathrm{CH}_{2}^{\circ}$ & 0.036383 & -376.333127 & & \\
\hline \multirow[t]{2}{*}{6} & $\mathrm{CF}_{3} \mathrm{CF}_{2}(-\mathrm{H})$ & 0.037377 & -575.261538 & 437.5 & $431.4 \pm 4.3$ \\
\hline & $\mathrm{CF}_{3} \mathrm{CF}_{2}^{\circ}$ & 0.024502 & -574.602653 & & \\
\hline \multirow[t]{2}{*}{7} & $\mathrm{CH}_{3} \mathrm{CH}(-\mathrm{H}) \mathrm{CH}_{3}$ & 0.098735 & -118.740307 & 418.2 & $412.5 \pm 1.7$ \\
\hline & $\mathrm{CH}_{3} \mathrm{CH}^{\bullet} \mathrm{CH}_{3}$ & 0.084415 & -118.088786 & & \\
\hline \multirow[t]{2}{*}{8} & $\mathrm{CH}_{3} \mathrm{CF}(-\mathrm{H}) \mathrm{CH}_{3}$ & 0.091946 & -217.883463 & 415.7 & \\
\hline & $\mathrm{CH}_{3} \mathrm{CF}^{\bullet} \mathrm{CH}_{3}$ & 0.078611 & -217.232857 & & \\
\hline \multirow[t]{2}{*}{9} & $\mathrm{CF}_{3} \mathrm{CH}(-\mathrm{H}) \mathrm{CH}_{3}$ & 0.078189 & -416.187769 & 432.9 & \\
\hline & $\mathrm{CF}_{3} \mathrm{CH}^{\circ} \mathrm{CH}_{3}$ & 0.064038 & -415.530644 & & \\
\hline \multirow[t]{2}{*}{10} & $\mathrm{CF}_{3} \mathrm{CF}(-\mathrm{H}) \mathrm{CH}_{3}$ & 0.071062 & -515.319969 & 426.4 & \\
\hline & $\mathrm{CF}_{3} \mathrm{CF}^{\circ} \mathrm{CH}_{3}$ & 0.057878 & -514.665299 & & \\
\hline \multirow[t]{2}{*}{11} & $\mathrm{CF}_{3} \mathrm{CH}(-\mathrm{H}) \mathrm{CF}_{3}$ & 0.056988 & -515.319969 & 450.1 & \\
\hline & $\mathrm{CF}_{3} \mathrm{CH}^{\bullet} \mathrm{CF}_{3}$ & 0.042791 & -514.665299 & & \\
\hline \multirow[t]{2}{*}{12} & $\mathrm{CF}_{3} \mathrm{CF}(-\mathrm{H}) \mathrm{CF}_{3}$ & 0.049688 & -812.743758 & 438.9 & \\
\hline & $\mathrm{CF}_{3} \mathrm{CF}^{\circ} \mathrm{CF}_{3}$ & 0.036805 & -812.084347 & & \\
\hline \multirow[t]{2}{*}{13} & $\left(\mathrm{CH}_{3}\right)_{3} \mathrm{C}(-\mathrm{H})$ & 0.125694 & -157.935666 & 413.0 & $403.8 \pm 1.7$ \\
\hline & $\left(\mathrm{CH}_{3}\right)_{3} \mathrm{C}^{\bullet}$ & 0.111806 & -157.286094 & & \\
\hline \multirow[t]{2}{*}{14} & $\left(\mathrm{CH}_{3}\right)_{2}\left(\mathrm{CF}_{3}\right) \mathrm{C}(-\mathrm{H})$ & 0.105086 & -455.382926 & 423.7 & \\
\hline & $\left(\mathrm{CH}_{3}\right)_{2}\left(\mathrm{CF}_{3}\right) \mathrm{C}^{\bullet}$ & 0.091369 & -454.729292 & & \\
\hline \multirow[t]{2}{*}{15} & $\left(\mathrm{CH}_{3}\right)\left(\mathrm{CF}_{3}\right)_{2} \mathrm{C}(-\mathrm{H})$ & 0.082843 & -752.818908 & 438.4 & \\
\hline & $\left(\mathrm{CH}_{3}\right)\left(\mathrm{CF}_{3}\right)_{2} \mathrm{C}^{\bullet}$ & 0.070363 & -752.159692 & & \\
\hline \multirow[t]{2}{*}{16} & $\left(\mathrm{CF}_{3}\right)_{3} \mathrm{C}(-\mathrm{H})$ & 0.062235 & -1050.242098 & 449.9 & \\
\hline & $\left(\mathrm{CF}_{3}\right)_{3} \mathrm{C}^{\bullet}$ & 0.049262 & -1049.578489 & & \\
\hline
\end{tabular}

${ }^{a}$ The dissociating $\mathrm{H}$ atom is shown in parentheses. ${ }^{b} \mathrm{HF} / 6-31 \mathrm{G}(\mathrm{d})$ zero-point energy, scaled by $0.8929 .{ }^{c}$ In hartrees $(1 \mathrm{hartree}=2625.5 \mathrm{~kJ} / \mathrm{mol})$. ${ }^{d}$ Energy (including ZPE) at MP2/6-311+G(3df,2p)//MP2/6-31G(d) level. ${ }^{e}$ Calculated bond dissociation energies (at $298.15 \mathrm{~K}$ ), in kJ/mol. ${ }^{f}$ Experimental bond dissociation energies (at $298.15 \mathrm{~K}$ ), in kJ/mol; from refs 10 (HFCs) and 24 (alkanes). ${ }^{g}$ Experimental BDE (ref 9) used as reference.

However, this generally leads to unacceptably large systematic errors using even the largest basis sets (or compound methods such as G2) that are feasible for chemically interesting species.

Fortunately, these systematic errors in calculated BDEs (or other energy differences between species) may be largely eliminated via the application of "isodesmic" reactions, ${ }^{19,20}$ in which the number of each bond type is conserved. For such processes the desired energy difference may be referenced to one whose value has been measured accurately. To obtain $\mathrm{C}-\mathrm{H}$ BDEs in the fluoroalkanes, one may use the following exchange reaction:

$$
\mathrm{RH}+\mathrm{CH}_{3}^{\cdot} \rightarrow \mathrm{R}^{\bullet}+\mathrm{CH}_{4}
$$

The change in $a b$ initio absolute energy (including ZPE) is equal to the enthalpy change at $0 \mathrm{~K} ; \Delta E_{0}=\Delta H^{\circ}(0 \mathrm{~K})$. The dissociation enthalpy $D_{0}($ at $0 \mathrm{~K})$ is then obtained from the expression

$$
D_{0}(\mathrm{R}-\mathrm{H})=\Delta H^{\circ}(0 \mathrm{~K})+D_{0}\left(\mathrm{CH}_{3}-\mathrm{H}\right)_{\exp }
$$

where the experimental $D_{0}\left(\mathrm{CH}_{3}-\mathrm{H}\right)$ is accurately known. ${ }^{21}$ To determine BDEs at $298.15 \mathrm{~K}$, we adopted the recommendation contained in ref 20 , and use the relation

$$
D_{\mathrm{T}} \approx D_{0}+2.5 R T
$$

In this treatment only differences in thermal energies arising from the translational and rotational modes are considered, the minuscule contribution from the lost $\mathrm{C}-\mathrm{H}$ vibration is ignored, and the contributions of other vibrations and internal rotations are assumed to be the same in the stable molecule and the radical.

This treatment was tested for $D_{298}\left(\mathrm{CF}_{3} \mathrm{CF}_{2}-\mathrm{H}\right) . \mathrm{HF} / 6-31 \mathrm{G}(\mathrm{d})$ data for $\mathrm{CF}_{3} \mathrm{CF}_{2} \mathrm{H}$ yield the torsional mode frequency of $72 \mathrm{~cm}^{-1}$ and the reduced moment of inertia of $6.0 \times 10^{-46} \mathrm{~kg} \mathrm{~m}^{2}$, which correspond $^{22}$ to a 3 -fold rotational barrier of $14.7 \mathrm{~kJ} \mathrm{~mol}^{-1}$. A hindered rotor treatment ${ }^{23}$ yields $H_{298}-H_{0}=18.9 \mathrm{~kJ} \mathrm{~mol}^{-1}$. A similar analysis by Chen et al. ${ }^{14}$ yielded $H_{298}-H_{0}=18.6$ $\mathrm{kJ} \mathrm{mol}{ }^{-1}$ for $\mathrm{CF}_{3} \mathrm{CF}_{2}$. These results imply $D_{298}=D_{0}+5.9 \mathrm{~kJ}$ $\mathrm{mol}^{-1}$, only $0.3 \mathrm{~kJ} \mathrm{~mol}^{-1}$ below the value obtained from eq 4 . Thus errors from the assumptions appear quite small.

Experimental BDEs in the fluoromethanes, as well as values obtained from eq 2 using G2 energies, are contained in the second and third columns of Table 1 . Considering the very large uncertainties in the measured bond enthalpies, resulting from difficulties in the measurement of accurate heats of formation for fluoromethane molecules and radicals, the agreement is very satisfactory; calculated values lie at or within the reported uncertainties. ${ }^{9,10}$ The agreement for $D_{298}\left(\mathrm{CF}_{3}-\mathrm{H}\right)$ shows that this level of theory satisfactorily accounts for changes in carbon hybridization, from $\mathrm{sp}^{2}$ in $\mathrm{CH}_{3}$ to $\mathrm{sp}^{3}$ in $\mathrm{CF}_{3}$.

The G2 method is too computationally intensive to be employed in the calculation of $\mathrm{C}-\mathrm{H}$ bond enthalpies in large polyfluoroalkanes. Therefore, to determine the level of computation (basis set and electron correlation treatment) required to obtain reasonably accurate BDEs, we have used the G2 (which approximates QCISD(T)/6-311+G(3df,2p)) values as a benchmark and tested various lower level calculations to determine how well they agree. As seen in the fourth column of Table 1, application of the MP2/6-311G(d,p) basis yielded 
values that were systematically lower than the G2 BDEs by $3-4 \mathrm{~kJ} / \mathrm{mol}$. Raising the level of electron correlation to QCISD(T) (column 5) did not materially improve the results. However, calculations at the MP2 level with the largest basis set employed in the G2 method, 6-311+G(3df,2p), yielded fluoromethane dissociation enthalpies that are in excellent agreement with the G2 enthalpies. Therefore, we have used MP2/6-311+G(3df,$2 p)$ for all further calculations on the fluoroethanes, propanes and isobutanes.

Comparison of the fifth and sixth columns of Table 2 shows there is generally good accord between the calculated and experimental $D_{298}$ values for hydrofluoroethanes ${ }^{10}$ and for propane ${ }^{24}$ and isobutane, ${ }^{24}$ with absolute deviations ranging from 1 to $9 \mathrm{~kJ} / \mathrm{mol}$ and a mean absolute deviation of $5.0 \mathrm{~kJ} / \mathrm{mol} .^{25}$

There are no measurements of $D_{298}\left(\mathrm{CHF}_{2} \mathrm{CH}_{2}-\mathrm{H}\right)$, but our value lies within $1.5 \mathrm{~kJ} / \mathrm{mol}$ of that calculated by Chen et al., ${ }^{12}$ and their computed $D_{298}\left(\mathrm{CH}_{2} \mathrm{FCH}_{2}-\mathrm{H}\right)$ is similarly close to our value. This good agreement is not surprising since they also utilized isodesmic reactions, albeit with a smaller basis set. Bond additivity corrections are an alternative way to remove systematic errors in BDEs, and the mean absolute deviation between our $D_{298}$ values for hydrofluoroethanes and those derived via the BAC-MP4 approach ${ }^{10}$ is $1.4 \mathrm{~kJ} / \mathrm{mol}$. These agreements suggest the $D_{298}$ values derived here for $\mathrm{C}_{3}$ and $\mathrm{C}_{4}$ species are reliable. The experimental values for $\mathrm{C}_{1}$ and $\mathrm{C}_{2}$ species lie within $\pm 6 \mathrm{~kJ} / \mathrm{mol}$ of our calculated values. Allowing for greater errors in the larger molecules, we propose $\pm 10 \mathrm{~kJ} / \mathrm{mol}$ error limits for $D_{298}$. Martell et al. ${ }^{15}$ reported calculated BDEs for hydrofluoroethanes that lie typically $10-20 \mathrm{~kJ} / \mathrm{mol}$ below our values. This deviation can be attributed in large part to their use of eq 1, which as noted above does not remove systematic errors in BDEs.

As stated above, one of the principal goals of this study was to ascertain how various structural factors affect the $\mathrm{C}-\mathrm{H}$ bond dissociation enthalpy in HFCs. A number of important trends are manifested in the results contained in Table 2. A comparison of BDEs of the nonfluorinated alkanes (nos. 1, 2, 7, and 13) reveals a marked drop in the $\mathrm{C}-\mathrm{H}$ bond stabilities with replacement of neighboring $\mathrm{H}$ atoms by methyl groups, arising from the well-known stabilization of the radical species by the inductive effect, ${ }^{28}$ which reflects $\sigma$ electron donation by the $-\mathrm{CH}_{3}$ groups. This is not a linear effect since, as shown in the table, the BDE is diminished by approximately $12 \mathrm{~kJ} / \mathrm{mol}$ with the first methyl group substitution (no. 2 vs no. 1), but is decreased by only $5 \mathrm{~kJ} / \mathrm{mol}$ with the addition of a third $-\mathrm{CH}_{3}$ (no. 13 vs no. 7).

One observes a reversed trend with replacement of the protons in methane by perfluoromethyl groups as displayed in the table (nos. 1, 5, 11, and 16) and in Figure 1. In this case, the BDEs increase with the degree of substitution, although the trend is more modest and saturates rather quickly; for example, there is a $9 \mathrm{~kJ} / \mathrm{mol}$ increase in the BDE with the addition of the first $-\mathrm{CF}_{3}$ group, but only a $2 \mathrm{~kJ} / \mathrm{mol}$ further increase with the addition of the second and third perfluoromethyl groups. The increased dissociation enthalpies with $-\mathrm{CF}_{3}$ substitution are attributable to the inductive electron-withdrawing tendency of this group, which destabilizes the radical.

The combined result of the two trends is that there is a rather dramatic rise in the BDE with successive replacements of $-\mathrm{CH}_{3}$ by $-\mathrm{CF}_{3}$ groups in fluoroalkanes. This is illustrated graphically in Figure 2 for the three series, $\left(\mathrm{CF}_{3}\right)_{x}\left(\mathrm{CH}_{3}\right)_{3-x} \mathrm{C}(-\mathrm{H})$, $\left(\mathrm{CF}_{3}\right)_{x}\left(\mathrm{CH}_{3}\right)_{2-x} \mathrm{CF}(-\mathrm{H})$, and $\left(\mathrm{CF}_{3}\right)_{x}\left(\mathrm{CH}_{3}\right)_{2-x} \mathrm{CH}(-\mathrm{H})$, where one finds average increases ranging from 11.5 to $16 \mathrm{~kJ} / \mathrm{mol}$ for each $-\mathrm{CF}_{3}$ substitution.

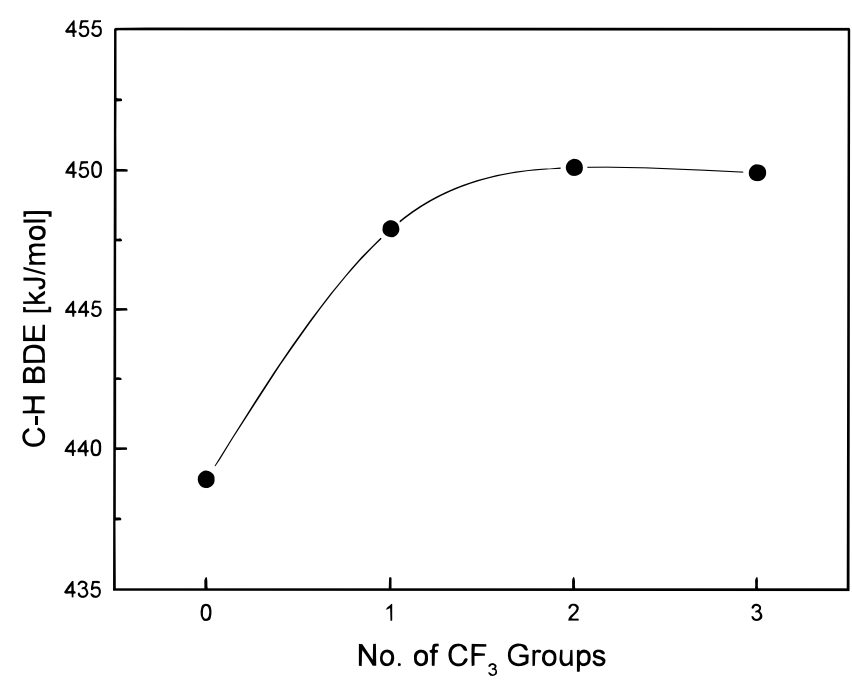

Figure 1. Effect of the replacement of $\mathrm{H}$ atoms by $-\mathrm{CF}_{3}$ groups on fluoroalkane $\mathrm{C}-\mathrm{H}$ bond dissociation enthalpies.

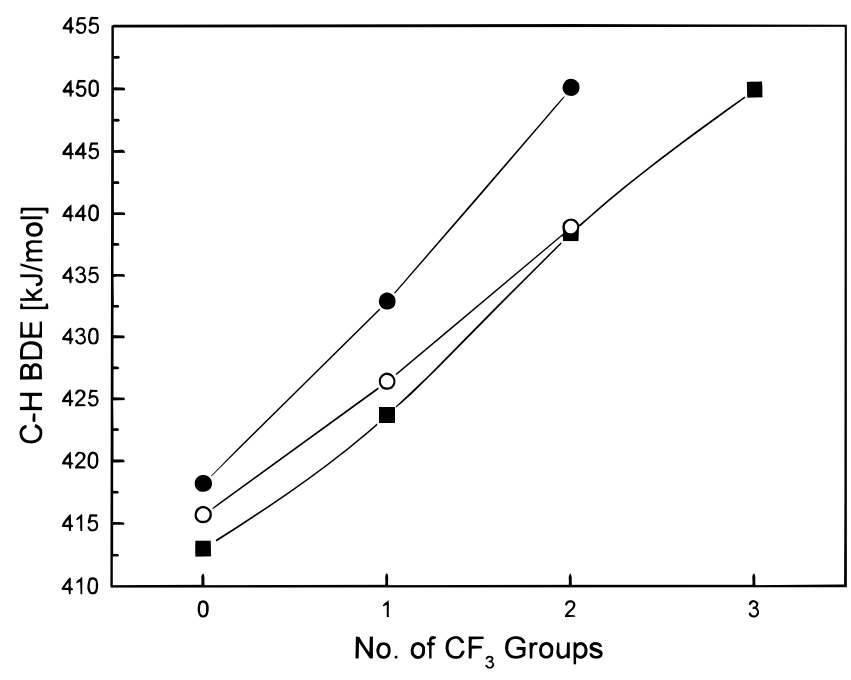

Figure 2. Effect of $-\mathrm{CH}_{3}$ by $-\mathrm{CF}_{3}$ group replacement on fluoroalkane $\mathrm{C}-\mathrm{H}$ bond dissociation enthalpies: $\left(\mathrm{CF}_{3}\right)_{x}\left(\mathrm{CH}_{3}\right)_{3-x} \mathrm{C}(-\mathrm{H}), \mathbf{\square} ;\left(\mathrm{CF}_{3}\right)_{x^{-}}$ $\left(\mathrm{CH}_{3}\right)_{2-x} \mathrm{CF}(-\mathrm{H}), \mathrm{O} ;\left(\mathrm{CF}_{3}\right)_{x}\left(\mathrm{CH}_{3}\right)_{2-x} \mathrm{CH}(-\mathrm{H})$,

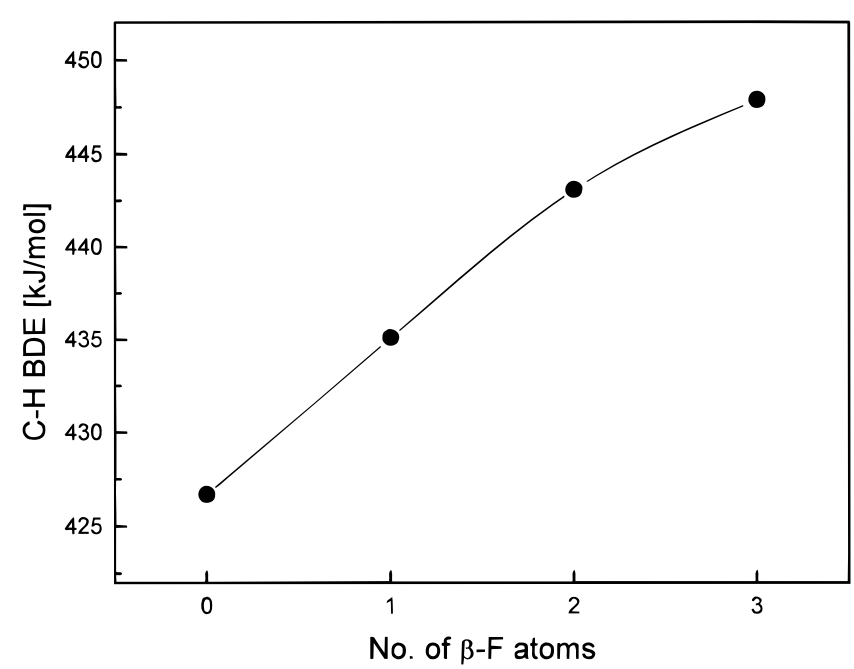

Figure 3. Dependence of fluoroethane $\mathrm{C}-\mathrm{H}$ bond dissociation enthalpies on the number of $\beta$-fluorines.

To explore further the effect of $\beta$-fluorine atoms on $\mathrm{C}-\mathrm{H}$ bond stability, we have determined BDEs in the series $\mathrm{CH}_{3-x} \mathrm{~F}_{x^{-}}$ $\mathrm{CH}_{2}(-\mathrm{H}), x=0-3$; the results are plotted in Figure 3. One observes that there is a monotonic (although not quite linear) 
increase in dissociation enthalpy with successive replacements of $\beta$-hydrogens by fluorine atoms, indicating, not surprisingly, that the inductive electron-withdrawing effects are roughly proportional to the number of fluorines on the neighboring $-\mathrm{CX}_{3}$ group.

Finally, it is of interest to determine the effect of $\alpha$-fluorine atoms on the $\mathrm{C}-\mathrm{H}$ dissociation enthalpies. A comparison of BDEs in three pairs of fluoropropanes which have either $-\mathrm{CH}_{2}-$ or $-\mathrm{CHF}-$ on the central carbon (nos. 7 and 8, 9 and 10,11 and 12) reveals that the replacement of a proton by an $\alpha$-fluorine in every case diminishes the $\mathrm{C}-\mathrm{H}$ dissocation enthalpy (by amounts ranging from 2.5 to $11.2 \mathrm{~kJ} / \mathrm{mol}$ ). This is also evidenced in a comparison of $\mathrm{CF}_{3} \mathrm{CH}_{2}(-\mathrm{H})$ with $\mathrm{CF}_{3^{-}}$ $\mathrm{CF}_{2}(-\mathrm{H})$, in which it is seen that the BDE of the latter fluoroethane is lower by $10.4 \mathrm{~kJ} / \mathrm{mol}$. The decreased $\mathrm{C}-\mathrm{H}$ bond stability induced by $\alpha$-fluorination may be attributed to the $\pi$-electron donor property of fluorine atoms, which acts to stabilize the radical species.

\section{Conclusions}

Ab initio energies obtained at the MP2/6-311+G(3df,2p) level of theory have been employed in isodesmic reactions to obtain $\mathrm{C}-\mathrm{H}$ bond dissociation enthalpies at $298 \mathrm{~K}$ for a variety of $\mathrm{C}_{1}-\mathrm{C}_{4}$ hydrofluorocarbons, with up to 13 heavy atoms. There is good accord with the experimental data that are available for $\mathrm{C}_{1}$ and $\mathrm{C}_{2}$ species, and the values predicted for $\mathrm{C}_{3}$ and $\mathrm{C}_{4}$ species are expected to be accurate to within $\pm 10 \mathrm{~kJ} / \mathrm{mol}$. Several relations between structure and BDE have been noted, and trends where $-\mathrm{H}$ and/or $-\mathrm{CH}_{3}$ groups are replaced by $-\mathrm{F}$ and/or $-\mathrm{CF}_{3}$ were rationalized in terms of the inductive effect, involving $\sigma$ and/or $\pi$ electron donation and withdrawal.

Acknowledgment. The authors thank the Robert A. Welch Foundation (Grants B-1174 (P.M.) and B-657 (M.S.)), the UNT Faculty Research Fund, the Air Force Office of Scientific Research, and the Materials Directorate at Wright Laboratory for financial support. This research was supported, in part, by high performance computing facilities at Wright Laboratory, Wright-Patterson AFB, OH, and by the DoD NAVO MSRC Center.

\section{References and Notes}

(1) Karecki, S.; Tao, B.; Reif, R. Experimental Approach to Identifying Alternatives for Dielectric Film Etching and Chamber Cleaning; SRC/MIT Technology Transfer Course: Reducing PFC Emissions through Chemistry
Replacement; Massachusetts Institute of Technology: 1995.

(2) CFC-Halon News 1996, 6, 8.

(3) Berry, R. J.; Burgess, D. R. F., Jr.; Nyden, M. R.; Zachariah, M.

R.; Schwartz, M. J. Phys. Chem. 1995, 99, 17145.

(4) Berry, R. J.; Burgess, D. R. F., Jr.; Nyden, M. R.; Zachariah, M.

R.; Melius, C. F.; Schwartz, M. J. Phys. Chem. 1996, 100, 7405.

(5) Berry, R. J.; Schwartz, M. Struct. Chem., submitted.

(6) Berry, R. J.; Ehlers, C. J.; Burgess, D. R.; Zachariah, M. R.; Marshall, P. Chem. Phys. Lett., in press. 48.

(7) Marshall, P.; Misra, A.; Berry, R. J. Chem. Phys. Lett. 1997, 265,

(8) Ravishankara, A. R.; Lovejoy, E. R. J. Chem. Soc., Faraday Trans. 1994, $90,2159$.

(9) Gurvich, L., Veyts, I. V., Alcock, C. B., Eds. Thermodynamic Properties of Individual Substances: Hemisphere Pub. Corp.: New York, 1991.

(10) Zachariah, M. R.; Westmoreland, P. R.; Burgess, D. R., Jr.; Tsang, W.; Melius, C. F. J. Phys. Chem. 1996, 100, 8737.

(11) Chen, Y.; Rauk, A.; Tschuikow-Roux, E. J. Chem. Phys. 1990, $93,1187$.

(12) Chen, Y.; Rauk, A.; Tschuikow-Roux, E. J. Chem. Phys. 1990, 93, 6620 .

(13) Chen, Y.; Rauk, A.; Tschuikow-Roux, E. J. Chem. Phys. 1991, 94, 7299 .

(14) Chen, Y.; Rauk, A.; Tschuikow-Roux, E. J. Chem. Phys. 1991, 95, 2774.

(15) Martell, J. M.; Boyd, R. J.; Shi, Z. J. Phys. Chem. 1993, 97, 7208.

(16) Frisch, M. J.; Trucks, G. W.; Schlegel, H. B.; Gill, P. M. W.; Johnson, B. G.; Robb, M. A.; Cheeseman, J. R.; Keith, T. A.; Petersson, G. A.; Montgomery, J. A.; Raghavachari, K.; Al-Laham, M. A.; Zakrzewski, V. G.; Ortiz, J. V.; Foresman, J. B.; Cioslowski, J.; Stefanov, B. B.; Nanayakkara, A.; Challacombe, M.; Peng, C. Y.; Ayala, P. Y.; Chen, W.; Wong, M. W.; Andres, J. L.; Replogle, E. S.; Gomperts, R.; Martin, R. L.; Fox, D. J.; Binkley, J. S.; Defrees, D. J.; Baker, J.; Stewart, J. J. P.; HeadGordon, M.; Gonzalez, C.; Pople, J. A. Gaussian 94, Revision A.1; Gaussian, Inc.: Pittsburgh, PA, 1995.

(17) Curtiss, L. A.; Raghavachari, K.; Trucks, G. W.; Pople, J. A. J. Chem. Phys. 1991, 94, 7221.

(18) Pople, J. A.; Scott, A. P.; Wong, M. W.; Radom, L. Isr. J. Chem. 1993, 33, 345 .

(19) Hehre, W. J.; Ditchfield, R.; Radom, L.; Pople, J. A. J. Am. Chem. Soc. 1970, 92, 4796.

(20) Hehre, W. J.; Radom, L.; Schleyer, P. v. R.; Pople, J. A. Ab Initio Molecular Orbital Theory; Wiley: New York, 1986.

(21) $D_{0}\left(\mathrm{CH}_{3}-\mathrm{H}\right)_{\text {exp }}=432.4 \pm 0.6 \mathrm{~kJ} / \mathrm{mol}$ was derived from experimental enthalpies of formation evaluated in ref 9.

(22) Benson, S. W. Thermochemical Kinetics, 2nd ed.; Wiley: New York, 1976. p 45

(23) Lewis, G. N.; Randall, M. Thermodynamics, 2nd ed.; revised by Pitzer, K. S.; Brewer, L.; McGraw-Hill: New York, 1961; Chapter 27.

(24) Berkowitz, J.; Ellison, G. B.; Gutman, D. J. Phys. Chem. 1994, 98, 2744.

(25) One may use the electronic energies in Table 2, together with $E(\mathrm{H})$ $=-0.499810$ hartrees and $E(\mathrm{~F})=-99.602117$ hartrees, to obtain BDEs directly via eq 1 . However, as discussed in the text, this approach is open to systematic error.

(26) Lowry, T. H.; Richardson, K. S. Mechanism and Theory in Organic Chemistry, 3rd ed.; Harper Collins: New York, 1987; Chapters 2 and 9. 